\title{
IDENTIFYING CONSTRAINTS FOR HOSPITAL INFECTION CONTROL MANAGEMENT VIA MCKINSEY 7S FRAMEWORK IN PAKISTAN
}

\author{
Shagufta Perveen ${ }^{1}$ and Shifa S Habib ${ }^{1}$
}

'Department of Community Health Sciences, Aga Khan University, PO Box 3500, Stadium Road, Karachi, Pakistan. Correspondence: shagufta.perveen@aku.edu

\begin{abstract}
Background: In Pakistan, structured guidelines for hospital infection control and prevention are deficient in most public sector facilities. There is dearth of literature available on management of hospital-care acquired infections and related issues. This study aims to understand infection control management as a proxy measure for quality of health care provided at a public sector tertiary care hospital in Karachi, Pakistan. In this study, we identify barriers to implementation of infection control measures and highlight key areas for quality improvement.

Methods: A cross sectional study was carried out in 2008 using qualitative research methods. In-depth interviews were conducted with hospital staff belonging to three different management tiers.

Results: There was lack of a centralized documented infection control policy, structure or management hierarchy in the hospital. The infection control mechanisms were managed at the individual ward level depending upon the interest of the individual Head of the Department. Lack of well-defined systems for human resource and financial management, resource allocation, documentation, communication, monitoring and evaluation for infection control further augmented the problem.

Conclusion: Based on the results of this study, it is evident that quality infection control mechanisms must be organized and controlled at the hospital level not at the individual ward level. Human resource recruitment and training, budgetary allocation and designing of communication channels specific to infection control are needed at this tertiary care hospital. This is the first study to understand the management perspective for hospital infection control using 7S McKinsey framework of management in the largest tertiary care public sector hospital in Sindh

Keywords: Mckinsey 7s framework, infection control, hospital management, quality of healthcare, Pakistan
\end{abstract}

\section{Introduction}

Rates of Health Care-Associated Infections (HCAls) are considered key quality indicators of patient care. Worldwide, more than 1.4 million people suffer from HCAls annually $(1,2)$. HCAls are the most common complication and a substantial cause of mortality and morbidity among hospitalized patients (3). The mortality and morbidity burden associated with HCAls adds on to the direct and indirect costs to the health care systems across the globe. Excessive length of stay, functional disability, increased resistance to antibiotics, emotional stress of the patient, high mortality, increased healthcare costs for patients and their families with massive additional financial burden for health care systems (4-6) are some of its undesirable consequences.

High income and resource-poor countries both are confronted with the burden of HCAls. Out of every 100 hospitalized patients, seven in high income countries (HICs) and 10 in low and middle income countries (LMICs) acquire at least one $\mathrm{HCAl}(6)$.
Growing volumes of HCAls worldwide, especially in LMICs like Pakistan, pose a major barrier to the delivery of quality care for the already distressed health care systems of these countries, where a significant proportion of the population relies on the publicly funded services for health care needs. Most frequently affected by these infections are high-risk populations, such as patients admitted in intensive care units (ICUs) and newborns (6). The incidence of ICU-acquired infections is at least two to three times and incidence of neonatal $\mathrm{HCAl}$ is three to 20 times higher in LMICs than in HICs (6). Surgical site infection is the most frequent HCAl in LMICs (WHO, 2011). Currently there is dearth of evidence at country level to evaluate the total impact of $\mathrm{HCAl}$ in LMICs. Systematic review by WHO shows that $66 \%(97 / 147)$ of LMICs lack any published data on endemic burden of HCAls (WHO 2011). Surveillance systems for HCAls are virtually nonexistent in most LMICs, with only 23 LMICs having reported a functioning HCAI national surveillance system (6). Infection control 
(IC) frameworks are absent at the policy and practice level, particularly in resource-poor settings. Further aggregating the situation is a lack of political will to plan, implement and provide financial support for such initiatives.

A study conducted in five district hospitals of northern Thailand showed that the IC practices were largely inappropriate and the participating hospitals lacked competent personnel and adequate administrative support for IC (7). Another study from Italy reported suboptimal essential infrastructure for IC, along with poor hand washing practices and little diagnostic support services to tackle HCAls (8).

Standard guidelines for suitable implementation of IC in hospital settings, have been laid down by different international organizations, like World Health Organization, Centre for Disease Control and Joint Commission for International Accreditation (9-16), appropriate compliance with which, can bring significant reduction in HCAls. The primary objective of a hospital infection control (IC) program is to identify and reduce the risk of acquiring and transmitting infections among patients, personnel and visitors and serve as the paradigm for hospital-wide quality control. Enforcement of stringent quality standards in IC practices can significantly reduce incidence of HCAls and improve overall quality of care (17).

Pakistan is a low middle-income country with a population of 192 million that continues to increase exponentially (18). Pakistan houses a mixed health care system, comprising both public and private health facilities with the latter being dominant and $60 \%$ of all health care expenditure are made out of pocket (19). There is a three-tiered public healthcare delivery system in Pakistan (20). This includes Basic Health Units (BHUs) and Rural Health Centers (RHCs), forming the core of the primary healthcare model. Tehsil Headquarter Hospitals (THQHs) and District Headquarter Hospitals (DHQHs) are first and second referral facilities providing acute, ambulatory and inpatient care. Tertiary care facilities include teaching hospitals that mainly provide curative services and subspecialty care. There are a total of $947 \mathrm{THQH}$ and $\mathrm{DHQH}$ and 29 teaching care hospitals in Pakistan (21). Taxation and out-of pocket payments are the major modes of financing health within the country (22).

The state of IC in public sector hospitals in Pakistan is largely inadequate, whereby HCAls present a significant health problem along with the emergence of multi-drug resistant bacteria (23). There is also a high occurrence of Methicillin Resistant Staphylococcus Aureus (MRSA) and ICU infections among hospitalized patients in Pakistan $(24,25)$. Reported rates of neonatal infections in Pakistan are 3-20 times higher than those reported for hospital-born babies in HICs (26). In Pakistan, welldefined guidelines for hospital IC and prevention are nonexistent in the public sector facilities (23). Evidence from HICs suggests that strategic management is essential to address the problem of HCAls. However, little literature is available from Pakistan on HCAls management and related issues. Surveys have been conducted locally focusing on rate of infections and clinical skills (27). Given the dearth of evidence on the relationship between IC practices and the risk of HCAls in Pakistan, this study aimed to understand IC management as a proxy of quality of health care at a public sector tertiary care hospital in Karachi, Pakistan and identify factors which impede proper implementation of IC measures and highlight some areas for quality improvement.

\section{Methodology}

Study Site: This study was conducted at the largest tertiary care public sector hospital in Karachi, the largest city and the economic hub of Pakistan with an estimated population of over 23 million (28). The tertiary care hospital under study is one of the biggest and oldest teaching hospitals in Pakistan. Established in 1898, the hospital has 39 wards and caters to an estimated 5000 patients on an outpatient basis per day. With an overall capacity of 1758 beds, the actual number of admitted patients is about 2820 (29). The wards are chronically crowded, enhancing the risk of acquiring HCAls. Medical Superintendent (MS) is the administrative head of the hospital. Additional Medical Superintendents (AMS), under the supervision of MS looks after various sections of administration. Deputy Medical Superintendents (DMS) are the substitutes for AMS in the evening and during night shifts. Each ward is supervised by departmental heads who are professors or associate professors and fall under the management of the university. The overall state of $\mathrm{IC}$ in this hospital is dismal with little compliance with the infection control guidelines. A recent study reported that health care workers neither practice hand washing nor consider it important for infection control. (30).

Study Sample: In order to understand the infection control management a cross sectional study was carried out in 2008 using qualitative research methods. In-depth interviews were conducted with hospital staff belonging to three different management tiers. These included (i) personnel from higher management including medical superintendent (MS), additional medical superintendent (AMS) and deputy medical superintendent (DMS) (ii) head of the departments (HODs) of different wards and (iii) personnel from lower management including nursing superintendent, technician incharges, steward, OPD incharge and the statistical officer.

Through purposive sampling, only those staff members were selected for interviews who had completed a minimum of three years in service and were associated with functioning and management of the hospital. Those on vacations, transferred or retired were excluded.

Ensuring representation from all three levels of management a total of 20 in-depth interviews were conducted till the point of saturation.

Theoretical framework of the study: In order to 
understand IC management at the study site, we used McKinsey $7 S$ framework of management (Fig 1): a value-based model with seven elements, aiming to provide a succinct overview of the organization (31).
The seven elements of McKinsey framework are summarized in table 1.

\section{Data Collection Procedures: A semi-structured}

\section{Table 1: Seven elements of McKinsey Framework}

\begin{tabular}{|c|c|c|c|}
\hline S. No. & $\mathbf{S}$ & Description & Questions and Probes in the interview questionnaire \\
\hline 3. & Systems & $\begin{array}{l}\text { Formal and informal procedures that } \\
\text { support the strategy and structure. }\end{array}$ & $\begin{array}{l}\text { Financial / Human resource / Documentation / } \\
\text { Communication / Monitoring and evaluation systems }\end{array}$ \\
\hline 5. & Staff & $\begin{array}{l}\text { Human resource management } \\
\text { processes - training and development } \\
\text { process, socialization process, how new } \\
\text { managers are introduced to the } \\
\text { organization, how they are helped in their } \\
\text { career planning. }\end{array}$ & $\begin{array}{c}\text { Positions to be filled for hospital infection control staff? } \\
\text { - } \quad \text { Process for infection control staff recruitment? } \\
\text { - } \quad \text { Guidelines/criteria/issues/challenges for } \\
\text { recruitment }\end{array}$ \\
\hline 6. & Skills & $\begin{array}{l}\text { Competencies prevailing in the } \\
\text { organization and how these are being } \\
\text { developed and expanded by the } \\
\text { organization. }\end{array}$ & $\begin{array}{l}\text { Qualified/trained infection control staff (infectious diseases } \\
\text { consultant, epidemiologist. Infection control nurse) } \\
\text { - How are the skills are monitored and assessed? }\end{array}$ \\
\hline
\end{tabular}

questionnaire was developed based on McKinsey's seven dimensions to explore participants' views and opinions about the IC practices at the hospital. There were 32 open-ended questions with relevant probes, focusing on each dimension of the McKinsey framework. (Table 1). The questionnaire was pretested on three persons before its implementation.

Content analysis: All interviews were transcribed into English language. All transcripts were read thoroughly and short notes were made at the points of noteworthy and relevant information. The data analysis process was adapted from Braun and Clark's thematic analysis method that led to the researchers getting familiarized with the data, generating codes, searching, reviewing and naming themes [20]. Relevant probes were picked from the transcribed data using the software QSR NViVo version 10 and linked to the identified themes. All disagreements were discussed among the authors until consensus was reached on the overall analysis. Categorization of data led to the emergence of themes. All the transcripts were reviewed again in the end to make sure that the necessary information had been captured.

Ethical Considerations: The study was approved by the ethical review committee of the Aga Khan University (ERC reference no. 1007-CHS/ERC-08). Informed written consent was provided by all of the participants. Two persons refused to participate in the study. Formal 
administrative approval was taken from hospital's administration prior to beginning of the study.

\section{Results}

Analysis of in-depth interviews in light of $7 \mathrm{~s}$ McKinsey framework of management led to the identification of various themes. Interview results are organized under the umbrella of McKinsey 7s framework of management. 1.Strategy:

A proper and centralized documented IC policy, structure or management hierarchy is not in place at the hospital under study. As a consequence, the IC is managed on adhoc basis and at the individual ward level depending upon the interest of the individual HOD. HODs try to control infections through their practices and by teaching students.

"No concrete policy that has been there till date and at the department level different HODs

have their own policy as far as infection control is concerned." (HOD)

Participants reported that infectious and non-infectious waste is segregated and gloves are provided to the lower management staff. Incinerator is in place for infectious waste disposal, which is very old and needs repair quite often. Two participants from lower management mentioned that the higher management gives them verbal guidelines for cleaning of wards and waste disposal and they follow those guidelines. The lower management participants highlighted waste management as the only IC strategy that exists in this hospital. All study participants mentioned that the higher management has got complete authority to make any kind of decisions in order to formulate or deformulate IC strategies at the hospital level. But lack of interest and attention in this area at government level and dual control of the hospital are the main reasons for nonexistence of any IC strategy at the hospital.

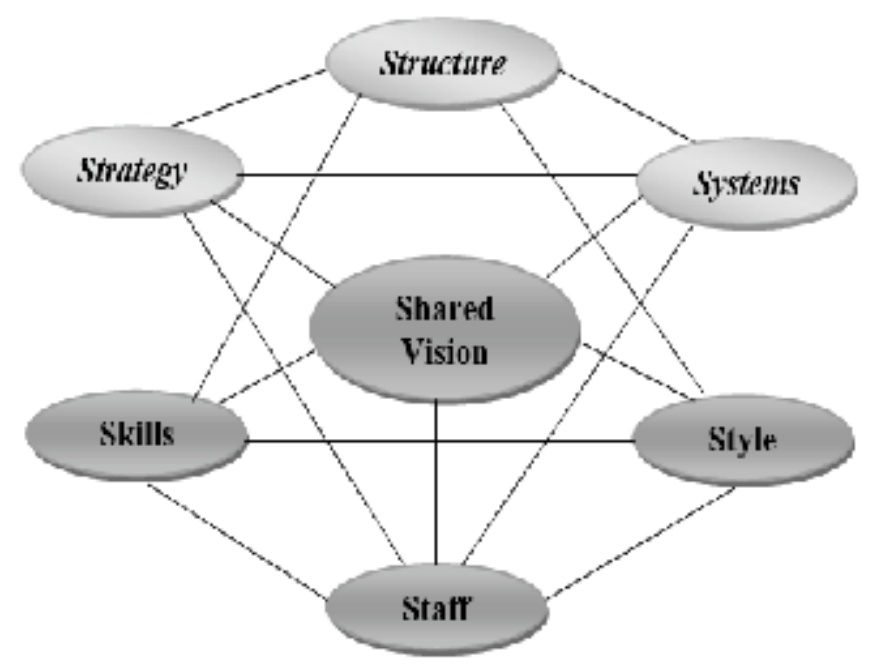

Fig 1: McKinsey 7s Framework
"Nobody has given attention to how many parameters are there for increased morbidity. No attention!" (HOD) 2.Structure:

Any structure or management hierarchy for the control of infections is absent at the hospital studied.

"The hospital does not have an infection control committee which is active, although a committee is there on paper but it is non - functional actually to work for hospital infection control." (Higher management official) Majority of the participants underlined a strong need for formulation of an IC committee and a team to oversee IC practices in this tertiary care government hospital. All three groups of participants consistently reported lack of coordination among various departments for IC activities.

"Hospital administration's involvement is less, otherwise on personal basis we coordinate in

case of a problem but for regular IC activities, no such thing! And this is needed on regular

basis." (HOD)

Main reason identified by the higher management for this lack of coordination is the utter non-existence of the concept of IC. HODs stated that poor administrative control, less awareness about the importance of IC and lack of facilities are among the reasons for this poor coordination among various departments of the hospital. Although the management is authorized to formulate or deformulate IC strategies but lack of interest and dual control come across as the two main hindrances as per the study participants.

"Because the hospital has more than one administrative control; MS, Secretariat and University, it gives problem in coordination. If single control would be there then it can have

a proper system." (Higher management official)

As a consequence, the IC is managed on ad hoc basis and at the individual ward level.

"Mainly at the department level, whoever is running the department has his/her own rules

and regulations." (HOD) "It's on ward level, it is not such that, things are not there, they are present but haphazardly and focally in wards." (HOD)

3.Systems:

Lack of well-defined systems for human resource and financial management, resource allocation, documentation, communication, monitoring and evaluation for IC further complicate the IC situation at the hospital studied.

Most of the higher management staff stated that there is no budget ary allocation for IC expenses. However, only a small proportion from the available budget is utilized for IC but is largely inadequate. Waste management is managed through the user fee (one rupee per OPD slip is charged from the patients coming to the hospital). The money collected by the "perchi clerk" in the OPD is deposited in the accounts office on daily basis, after which there is no system for its accountability. Majority of the HODs claimed that resource allocation for the 
hospital, as a whole, is insufficient to fulfill the needs of such a large tertiary care hospital. HODs have to make efforts on an individual level to generate funds for IC of their own ward. The lower management representatives affirmed the inadequacy of resources to establish effective IC mechanisms.

"It (given budget) is not utilized properly because if utilization is proper or had been proper then the number of infections had been reduced drastically" (HOD)

Absence of a formal human resource department in the hospital hampers effective management of human resource for IC. Different AMS manage human resource for their own working heads. Majority of HODs said that the human resource is there but there is a lack of coordinated human resource management for IC further complicates IC in the hospital.

"As such there is no HR department". "Even if there is something, it's haphazard" (Higher management official) Those staff members who are present can be utilized in a more effective manner to improve the situation. On the contrary, respondents from lower management highlighted that the current human resource is insufficient to maintain appropriate functioning of a large-scale tertiary care hospital.

Lack of any system for record keeping for NCls or culture of e-data for documentation was reported at this tertiary care hospital. Usually outbreaks of NCls go unidentified. "What happens in the hospital, nobody knows .As far as record and data is concerned, when nobody is there then from whom we will give the record and data?" (HOD)

One participant from the higher management informed that there is manual documentation of communicable diseases; he said "There is no documentation of $\mathrm{NCls......} \mathrm{Presently,} \mathrm{we} \mathrm{send} \mathrm{proformas} \mathrm{to} \mathrm{the} \mathrm{ward}$ which is the only information we have". This proforma is sent to the wards intermittently but not regularly and the collected information is entered in the computer by the statistical officer. There is no computerized system of documentation at the ward level. All the HODs affirmed absence of documentation for $\mathrm{NCls}$. They said that there is some documentation for communicable diseases like hepatitis $B$ and $C$ on individual ward basis but that is manual and not suitably organized. All respondents denied the presence of any surveillance program for $\mathrm{NCls}$. Lack of coordination at the hospital level and attention of the hospital administration are the major reason highlighted by all of the respondents for absence of a surveillance program at the hospital, due to which, the NCls go unidentified. Unwarranted use of antibiotics is also a common practice in the hospital. One of the participants pointed out that lack of data collection and research activities can be another reason. It was reported by the HODs that if there is some sort of record keeping it is usually the mortality and morbidity figures at the individual ward level, compiled according to interest of the HOD but there is no surveillance for $\mathrm{NCls}$.

Furthermore, a proper system of communication is deficient at this hospital. No communication channels exist between HODs and upper management regarding IC activities at the hospital. Although they usually communicate for other administrative issues on personal basis and phone calls is the second mode of communication used at this hospital.

"Regarding infection control, nobody has communicated till date, we had no conversations with anyone." (HOD)

All of the higher management officials reported absence of any system to monitor the IC practices being followed at the hospital.

"There is no monitoring program of any type (for IC)." (Higher management official)

The HODs, in addition to mentioning the absence of any system for monitoring of IC practices also stated that there are some clinical audits conducted at ward level based on the discretion of the head of the department. Two respondents from this group reported that whenever there is some epidemic or when an issue, is highlighted by the media is only when the management takes notice of the event, otherwise there is no regular monitoring present.

"If you ask anybody what the infection rate is? There is no tool to find out.... No central clinical audit is there" (HOD)

All of the study participants reported that the communication and works ( $\mathrm{CnW}$ ) department (previously known as PWD i.e. public works department), functioning under government of Sindh is responsible for the maintenance of general hygiene and cleanliness of the hospital. They all expressed high level of dissatisfaction with the performance of the $\mathrm{CnW}$ department and mentioned it is not efficient enough to address the maintenance requirements of such a large hospital. Elaborating this issue further, one of the administrators from the higher management stated "Most important failure of this hospital is PWD... as they don't come under MS so they respond on their own, whenever they want to respond, they respond".

The HODs also mentioned that due to dearth of human and financial resources and lack of coordination between $\mathrm{CnW}$ and hospital administration, the situation is worsening day by day. Expressing dissatisfaction with the $\mathrm{CnW}$ department, one of the HODs stated that "It is from 20 years back, the hygienic condition was much better than what it is now". Also high patient influx and cosmic number of attendants makes the maintenance of the hospital increasingly difficult. Due to the stated reasons the HODs are compelled to undertake work which is out of their jurisdiction, further adding to their frustration.

According to the study participants, political pressures have a significant effect in the routine functioning of this hospital. Every time the government is changed, there are a lot of transformations in the administration on political basis, which affect smooth running and proper functioning of the hospital.

"Political influences have an effect on everything. If political influence will be decreased then overall system 
will be improved." (Higher management official)

Frequent transfers within the hospital administration lead to instability of the overall working process. As far as the IC is concerned, the higher management officials reflected that frequent transfers do not have any effect on IC because no policy or plan is in place for IC at the hospital. Elaborating this, one of the higher management officials stated "When there is no policy then there will be no effect!"

4.Style/Culture:

Employees were aware of, and acknowledged the importance of IC.

"In my opinion there is great importance of IC and if we have a protocol and proper policies for IC, we will be saving the misery of the patient, we will be saving death!" (HOD)

Concurrently, there expressed dissatisfaction over the current status of IC at the hospital studied.

"Backbone! Hospital is based on this [IC], prevention is better than cure and unfortunately we are not working on prevention." (Higher management official)

Generally, all the interviewees agreed that IC is exceedingly important for a hospital but the prevalent culture and the attitude of staff do not reflect this. The ignorance about this issue stems from various reasons including lack of awareness, lack of motivation and lack of satisfaction with pay scale and working environment at this tertiary care government hospital. "The incinerator machine which we have, previously all infectious waste including used drips, syringes, dressing things, it used to burn in that. Now, it is being sold, sweepers sell them......no check and balance on that! ... this is the major reason I am not satisfied" (Lower management representative)

Staff absenteeism is also prevalent due to lack of accountability. "Absenteeism is great! Because there is no accountability." (HOD) "People don't come, they are off for many days, nobody can do anything, half of the staff is not coming and most of the time they are safe" (HOD)

The lower management reported absenteeism as a barrier to infection control at the hospital but not as strongly as the other two categories of participants.

"Absenteeism is there. You cannot disqualify anyone in government job. You will be transferred but cannot be terminated. This is the satisfaction in government job... Political pressure is a lot that he is our man you cannot terminate him." (Lower management representative)

\section{Staff:}

Majority of the participants did not have an idea of specific positions that are needed to be filled to have proper IC at the hospital. All of them mentioned that the hospital needs highly qualified and suitably trained IC professionals. They also highlighted the need for creating posts for IC, at the secretariat level so the appointments can be facilitated for the hospital.

"The positions are needed to be created by the department of health for an 'epidemiologist' 'microbiologist'..." (Higher management official)

No strategies were formulated in order to motivate and retain proper IC personnel. An example of this being consistently reported by many respondents was that of ID consultant, who joined the hospital two years back but left within six months of joining. The consultant tried to develop a protocol for hospital IC but this initiative was discontinued upon his departure. This highlights the need to have sustainable strategies to motivate and retain IC personnel as highlighted by the study participants.

"No strategy to motivate/retain IC staff. People should be hired on merit base, with professional skills and attitude" (Higher management official)

6.Skills:

Employees are not assessed for their IC skills, nor are they trained or updated with refreshers to expand their competencies. There is no ongoing education and training programs present for the existing staff. As a corollary, the hospital lacks knowledgeable employees.

"There is no training program. In 1997 there was a training program for one week and after that nothing has been done in this aspect." (Lower management representative)

Some programs were initiated in past but they were not sustained due to various reasons like lack of "will", lack of funds and coordination, lack of human resource to train people, lack of IC department and dual control of the hospital, that is, the hospital administration and the affiliated medical university.

"There was an infection control program in 1999 in which workshops and presentations were arranged and the nursing staff was trained." (Lower management representative)

7.Shared Values:

Although IC is considered very important as one of the participants quoted that "cleanliness is half of faith" but it is neither taken as a shared responsibility, nor its importance is reflected in practical implementation. All of the higher and lower management staff reported that most employees consider standard IC practices essential at any tertiary care hospital but this value is limited to their ideas only. It is not reflected practically in the attitude of all the employees because of lack of training and awareness about IC.

"Nobody denies that!...but that value is not in practice, everything is in thinking, unless an organized system will be there, it cannot be implemented". (Higher management official)

Regarding strength of the value that IC is important, one of the higher management officials expressed "I think and to be very honest that is not so much!" HODs on the other hand reported that infection control is not shared as a value and although everyone is well aware but the attitude and practices are not illustrative of it.

"They don't have any concept about infection control..." (HOD) 


\section{Discussion}

Resource limitation, lack of awareness about IC and careless attitude of staff towards work are major barriers in the effective implementation of standard IC policies and practices (32).

Our study found pervasive deficit of knowledge about IC and its practices as a quality of care effort in the hospital studied. The prevailing concept of IC management at this hospital is synonymous with hospital waste management. Our study highlights that IC at this tertiary care setting needs to be brought to attention. Major coordination efforts are needed at the management level, to develop and implement suitable IC management strategies. To the best of our knowledge, this study presents the first in-depth inquiry into and description of management perspectives for IC at a hospital in Pakistan using McKinsey 7s framework of management. There is, however, some evidence which documents very poor IC and absence of any IC policies, ICC or any infectious diseases department (30) at this hospital. A large body of literature presents clinical audits of the hospitals (33) and studies in which the focus is on the clinical application of IC standards (34-38) and their hazards including the transmission of life threatening infections to patients and health care workers $(37,38)$. Some of these studies do incorporate presence of management structure for IC but have not focused on the management of IC practices.

There is no formal, national approach and no tangible managerial support from the health authorities for the control of $\mathrm{NCls}$ (39). The IC policy does not exist at health department level and hence is not existent in this hospital. The issue of hospital IC has been neglected due to lack of interest and coordination, considering dual control a problem in the implementation of IC practices. The university, which this teaching hospital is affiliated with, manages the academics whereas the management of IC is the responsibility of hospital administration. There is no initiative to formulate IC policy at the hospital level or implement a standard IC protocol such standards-based management and recognition (SBM-R) which is a practical management approach for improving the performance and quality of health services $(40,41)$. It has been implemented for hospital infection prevention (SBM-R IP) in some developing countries like Malawi, Afghanistan and Punjab Province of Pakistan and resulted in dramatic improvements in infection prevention and control practices in these countries (42).

A well established infrastructure is needed for hospital IC (43). The IC team or committee is nonexistent in the hospital and there are no efforts at any administrative level to develop an organized structure for IC. As a consequence IC activities are fragmented and managed on an adhoc basis, depending upon the individual interest of the head of each department. However, all their efforts are isolated, which mandates development of a centralized and well-coordinated system for IC management at the hospital.

IC needs to be prioritized along with establishment of a dynamic administration to improve the situation of IC as lack of administrative leadership is associated with reduced volume of IC activities in hospitals (44).

The hospital does not have any skilled or qualified IC personnel which is a major issue that impedes application of IC strategies in the hospital since there is evidence that IC control activities are much better managed in hospitals with dedicated patient safety and full-time IC staff (44). There are no positions specified for qualified trained IC staff at the level of health department therefore, such posts must be created so as to recruit best suited staff for the management and control of $\mathrm{NCls}$. Currently, the available staff is involved in waste management but there are no focused activities taking place in an organized manner to develop a proper system. At present, no strategies are followed to recruit, motivate and retain dedicated IC employees resulting in poor IC related practices of majority of the employees. Similarly, there is no faculty, department, training or skill development with regard to IC. The current employees can be re-designated and trained to focus and implement standard IC strategies. Incentivization of the employees can be a useful way to improve the compliance with standard IC protocols and to improve overall IC status of this tertiary care government hospital.

Although, IC was acknowledged as an important area by all the participants interviewed, however, it was not given enough value particularly in practice. Furthermore, the concept of IC is not developed enough to guide the employees and keep them practice prevention of infections as a coherent team. Due to ignorance in all areas, the IC is not engrained as a value among employees and hence not reflected in their attitude when it comes to practical implementation of IC standards.

Scope and Limitations of the study

This is the first study to understand the management perspective for IC using 7S McKinsey framework of management in the largest tertiary care public sector hospital in Pakistan. This framework can be used to study organizational management in other public sector hospitals.

The major limitations of this study were:

The findings are limited to one tertiary care hospital and may not be generalized to all hospitals in Pakistan. However, because the structural issues tend to be similar in public sector hospitals across the country, we would expect similar kind of constraints to be present at other public sector hospitals also. The study was conducted at one point in time. The individuals interviewed had various length of time of service and may not have complete understanding of the past circumstances which may have been better or worse. However, most of the persons interviewed had long association with the hospital and their views spread over a significant period of time. Interview responses can be 
subjective in ways that minimize or exaggerate the findings, however, as the study was conducted by a former student of the institution who has a full understanding of the context, it is unlikely that any responses were exaggerated minimized or distorted. Furthermore, there was striking uniformity among the statements of all respondents, further reinforcing the findings. Participants' hesitation in being audio-taped increased reliance on notes which may have resulted in loss of data during the interview itself.

\section{Conclusion}

Based on the results of this study, it is evident that quality IC needs to be translated into practice at the hospital management and administrative level. Any such initiative at one of the public sectors hospitals can prove to be an impetus for 'Quality oriented IC policymaking' and subsequently wide-scale adoption of such policies at other lower level health facilities. We advocate that infection control needs to be implemented at the public sector hospital as a quality care initiative using a holistic approach.

Streamlining communication among all the administrators and employees of the hospital regarding IC activities is a key strategy for devising an IC protocol for this hospital and then monitoring compliance with it.

The entire hospital system needs to be restructured around IC, incorporating stringent control knobs for IC management, for which it is integral for IC management to be controlled at the hospital level and not at the individual ward level. Currently, there are no separate budgetary allocations for IC, however resources can be pooled in from various other sources like NGOs and philanthropists to cover the expenses of IC management at the hospital. A hospital-wide surveillance system is required, along with a transparent mechanism for accountability to monitor the IC activities for all employees. We recommend adoption of participative style of management where it must be mandated for the managers to spend a certain fixed proportion of their time focusing on IC related activities. It needs an open, innovative and friendly culture to keep the employees motivated and committed to their work. The concept of IC needs to be emphasized in its entirety and the employees must be sensitized to incorporate IC as a 'value' in their profession. Ongoing trainings and education for IC practices is central to improving IC competencies of the current employees who can be redesignated and trained to focus and implement standard IC strategies at the hospital. Incentives can be helpful to ensure compliance with IC standards. Secondly, posts must be created at the government level for qualified and highly skilled IC staff that can devote their time specifically to IC activities, as the study revealed that no positions are specified for skilled IC personnel at the level of the health department, which is an important factor of not having proper IC at this hospital. Implementation of a comprehensive accreditation system at this hospital may also be essential to standardize IC practices at this hospital.

Way Forward: Studies which include implementers (doctors, nurses, sweepers, technicians) of IC practices would be a next step towards indepth understanding of the problems and needs of this hospital regarding IC management in a holistic manner. Future studies should look at outcome improvements such as morbidity and mortality reduction due to $\mathrm{NCls}$ by trying out interventions aimed at improving management practices, employee skills and patient satisfaction. Promotion of research activities in hospital management in our local context is a dire need of time. Moreover, there is a need to conduct collaborative research involving ministry of health and provincial government in order to explore the problems, issues, challenges and solutions at the provincial and national levels.

\section{References}

1. WHO. Prevention of hospital-acquired infections. A practical guide, 2nd ed. Geneva: World Health Organisation, Department of Communicable Disease, Surveillance and Response.; 2002. Report No.: World Health Organisation (WHO)

2. World Health Organization. Blood safety and clinical technology: guidelines on prevention and control of hospital associated infections. New Delhi: Regional Office for South-East Asia; 2002 Jan

3. Vincent JL, Rello J, Marshall J, Silva E, Anzueto A, Martin CD, et al. International study of the prevalence and outcomes of infection in intensive care units. JAMA. 2009 Dec 02;302(21):2323-9.

4. Ayliffe GAJ. Introduction. Control of Hospital Infection: A Practical Handbook, 4th ed. 4th ed. London: Arnold; 2000.

5. Inan D, Saba R, Gunseren F, Ongut G, Turhan $O$, Yalcin AN, et al. Daily antibiotic cost of nosocomial infections in a Turkish university hospital. BMC Infect Dis. 2005 Jan 31;5(1):5.

6. WHO. Report on the burden of endemic health care-associated infections worldwide: clean care is safer care. Geneva, Switzerland: World Health Organization, care PSawafsh; 2011 Contract No.: Document Number|.

7. Juntaradee M, Yimyaem S, Soparat P, Jariyasethpong T, Danchaivijitr S. Nosocomial infection control in district hospitals in northern Thailand. J Med Assoc Thai. 2005 Dec;88 Suppl 10:S120-3.

8. Moro ML, Petrosillo N, Gandin C, Bella A. Infection control programs in Italian hospitals. Infect Control Hosp Epidemiol. 2004 Jan;25(1):36-40.

9. CDC. Revised CDC guidelines for hand hygiene in health-care settings: Centers for Disease Control and Prevention; 2003 Mar 15 Contract No.: Document Number|. 
10. WHO. WHO guidelines for hand hygiene in health care settings. Geneva: World Health Organization; 2004 Dec 10 Contract No.: Document Number|.

11. WHO. Standard precautions for injection safety: World Health Organization, Network SIG; 2007 Jan Contract No.: Document Number|.

12. Best management practices for hospital waste: Washington State Department of Ecology; 2005 Oct Contract No.: Document Number|.

13. JCIA. Joint commission international accreditation standards for hospitals; 2007

14. WHO. Blood safety and clinical technology: guidelines on prevention and control of hospital associated infections. New Delhi: World Health Organization; 2002

15. CDC. Guidelines for environmental infection control in health-care facilities: recommendations of $\mathrm{CDC}$ and the healthcare infection control practices advisory committee (HICPAC). Atlanta, GA: U.S. Department of Health and Human Services, Centers for Disease Control and Prevention, Services USDoHaH; 2003 Contract No.: Document Number|.

16. Siegel JD, Rhinehart E, Jackson M, Chiarello L, Committee tHICPA. Guidelines for isolation precautions: preventing transmission of infectious agents in healthcare settings: Healthcare Infection Control Practices Advisory Committee (HICPAC); 2007

17. Gastmeier P, Geffers C, Brandt C, Zuschneid I, Sohr D, Schwab F, et al. Effectiveness of a nationwide nosocomial infection surveillance system for reducing nosocomial infections. Journal of Hospital Infection. 2006;64(1):1622.

18. Monthly bulletin of statistics. Pakistan Bureau of Statistics. Government of Pakistan. http://www.pbs.gov.pk/sites/default/files/other /monthly_bulletin/monthly_bulletin_of_statisti cs_august15.pdf; August 2015.

19. National Health Accounts Pakistan. Statistics Division, Pakistan Bureau of Statistics. Government of Pakistan; 2013-14.

20. Nishtar S. Choked pipes: reforming Pakistan's mixed health system. Karachi: Oxford University Press 2009.

21. WHO. Health systems profile-Pakistan. Regional health systems observatory-EMRO. 2007.

22. Nishtar S. The Gateway Paper; Health System in Pakistan - a Way Forward. Pakistan's Health Policy Forum and Heartfile. 2006.

23. Memon BA. Nosocomial infections in public sector hospitals: urgent need for structured and coherent approach to the problem. Raval Med J. 2006;31:81-4.

24. Shaikh JM, Devrajani BR, Shah SZA, Akhund $\mathrm{T}$, Bibi I. Frequency, pattern and etiology of nosocomial infection in intensive care unit: an experience at a tertiary care hospital. J Ayub Med Coll Abbottabad. 2008;20(4).

25. Ali AM, Abbasi SA, Arif S, Mirza IA. Nosocomial infections due to methicillin resistant Staphylococcus Aureus in hospitalized patients. Pak J Med Sci July-September. 2007;23(4):593-6.

26. Zaidi AK, Huskins WC, Thaver D, Bhutta ZA, Abbas Z, Goldmann DA. Hospital-acquired neonatal infections in developing countries. Lancet. 2005 Mar 26-Apr 1;365(9465):117588.

27. Mahmood A, Fazal ur R, Chughtai F. A survey of infection control practices in the delivery room and nursery to investigate and control the high rate of neonatal sepsis: an experience at a secondary care hospital. J Pak Med Assoc. 2008 May;58(5):237-40.

28. Brinkhoff T. The Principal Agglomerations of the World".citypopulation.de. City Population. . 2013 [updated 2013; cited 20168 April]; Available from: https://scholar.google.com.pk/ scholar?hl=en\&q=\%28+Brinkhoff $\% 2 \mathrm{C}+$ Thom as. $+\% 22$ The+Principal+Agglomerations + of $+t$ he+World\%22.citypopulation.de.+City+Popul ation.+\&btnG=\&as_sdt=1\%2C5\&as_sdtp=.

29. Aligi I. Civil hospital spends only $\overline{R s} 52$ on medicine per patient Daily Times. 2007 Dec 8.

30. Baqi S, Damani N, Khanani R, Shah SA, Patricia L. Infection control at a government hospital in Pakistan. [Survey]. In press 2007 Jan.

31. Peters TJ, Waterman RH Jr. The saving remnant: successful American companies. In search of excellence. New York: Harper \& Row Publisher; 1982. p. 10-2.

32. Zafar A, Aslam N, Nasir N, Meraj R, Mehraj V. Knowledge, attitudes and practices of health care workers regarding needle stick injuries at a tertiary care hospital in Pakistan. J Pak Med Assoc. 2008 Feb;58(2):57-60.

33. Madani TA, Albarrak AM, Alhazmi MA, Alazraqi TA, Althaqafi AO, Ishaq AH. Steady improvement of infection control services in six community hospitals in Makkah following annual audits during Hajj for four consecutive years. BMC Infect Dis. 2006;6:135.

34. Askarian M, Shaghaghian S, McLaws ML. Needlestick injuries among nurses of Fars province, Iran. Ann Epidemiol. 2007 Dec;17(12):988-92.

35. Ahmed R. Hospital waste management in Pakistan. In press 2007 Aug. 
36. Moro PL, Moore A, Balcacer P, Montero A, Diaz $D$, Gomez V, et al. Epidemiology of needlesticks and other sharps injuries and injection safety practices in the Dominican Republic. Am J Infect Control. 2007 Oct;35(8):552-9.

37. Azap A, Ergonul O, Memikoglu KO, Yesilkaya A, Altunsoy A, Bozkurt GY, et al. Occupational exposure to blood and body fluids among health care workers in Ankara, Turkey. Am J Infect Control. 2005 Feb;33(1):48-52.

38. Mishal Y, Yosefy C, Hay E, Catz D, Ambon E, Schneider R. Risk of transmission of viral disease by needle punctures and cuts in hospital health care workers. Harefuah. 1998 Nov 1;135(9):337-9, 408.

39. Memon BA. Nosocomial infections in public sector hospitals: urgent need for structured and coherent approach to the problem. RMJ: J Pak Med Assoc. 2006 Jul-Dec Jul-Dec;31(2).

40. Bossemeyer D, Necochea E. Standardsbased management and recognition: a field guide. JHPIEGO aaoJHU, editor.: JHPIEGO; 2005.

41. JHPIEGO, an affiliate of Johns Hopkins University. [cited 2008 Feb 06]; Available from: http://www.jhpiego.net/media/ focuson/sbmr_ovw200702.htm.

42. Necochea E, Tripathi V, Kim YM, Akram N, Hyjazi Y, da Luz Vaz M, et al. Implementation of the Standards-Based Management and Recognition approach to quality improvement in maternal, newborn, and child health programs in low-resource countries. Int $\mathrm{J}$ Gynaecol Obstet. 2015 Jun;130 Suppl 2:S1724.

43. Scheckler WE, Brimhall D, Buck AS, Farr BM, Friedman C, Garibaldi RA, et al. Requirements for infrastructure and essential activities of infection control and epidemiology in hospitals: a consensus panel report. 1998 Feb;26(1):4956.

44. Fukuda H, Imanaka Y, Hirose M, Hayashida K. Factors associated with system-level activities for patient safety and infection control. Health Policy. 2008 Jun 4. 